\title{
Theses spark twin dilemma for physicists
}

Declan Butler, Paris

Take a deep breath, and give the following sentence a go. "We demonstrate that the lorentzian signature of the space-time metric $(+++-)$ is not fixed at the Planck scale and shows 'quantum fluctuation' between the lorentzian and euclidean $(+++ \pm)$ forms until the 0 scale where it becomes euclidean $(++++)$." Confused? Don't worry, you're in good company. Physicists around the world have been unable to agree on whether the $\mathrm{PhD}$ thesis this line comes from is good, bad or a hoax.

Rumours began to circulate after Max Niedermaier, a physicist at the University of Tours in France, sent an e-mail on 22 October to Ted Newman, a physicist at the University of Pittsburgh. Niedermaier alleged that French twins Grichka and Igor Bogdanoff, science writers who starred in a popular 1980s science television programme, had "spoofed" their $\mathrm{PhD}$ theses.

The line above comes from the abstract to Grichka's thesis, for which he gained his $\mathrm{PhD}$ at Bourgogne University in 2000. Both this thesis and that of his brother, who gained his $\mathrm{PhD}$ from Bourgogne earlier this year, drew on areas of mathematics and theoretical physics to study the origin of the Universe. Niedermaier claimed that the theses, and four of the brothers' papers published recently in peerreviewed journals, had been concocted using jargon acquired from interviewing string theorists and other theoretical physicists.

"The abstracts are delightfully meaningless combinations of buzzwords ... which apparently have been taken seriously," Niedermaier wrote. The claim prompted a flurry of e-mails and Internet postings, with many physicists echoing Niedermaier's thoughts. After speaking to the Bogdanoffs, Niedermaier quickly issued an apology, acknowledging that he had not relied on "first hand information". But the message came too late.

With doubt hanging over the Bogdanoffs, physicists rushed to distance themselves from the twins' papers. The editorial board of Classical and Quantum Gravity took the unusual step of saying that a paper by the brothers had slipped through peer review "even though, in retrospect, it does not meet the standards expected of articles in this journal".

Frank Wilczek, editor-in-chief of the Annals of Physics and a theoretical physicist at the Massachusetts Institute of Technology (MIT), disowned another paper, arguing that it had been accepted by past management and would not have been accepted under him.

So are the papers good science or not? Enquiries by Nature show that few theoretical physicists, including some who reviewed the brothers' $\mathrm{PhD}$ theses, are completely certain. Jac Verbaarschot, of Stony Brook University in New York, reviewed Igor's PhD.

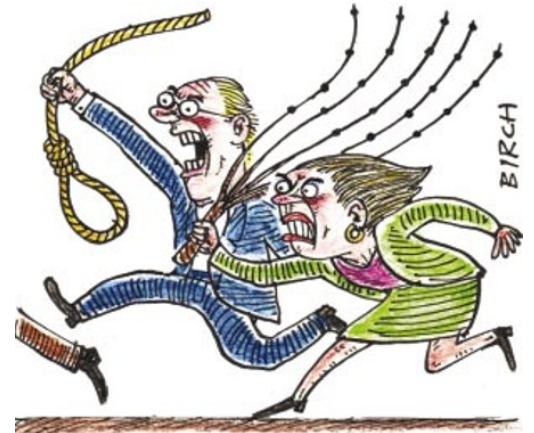

STRING THEORISTS DISCUSS KNOT THEORY WITH THE BOGDANOFF TWINS.

He says it contained original ideas, but claims that it was awarded in part because of Igor's contributions to the public understanding of science. Others have come to harsher conclusions. "They were at best wrong, and most likely just throwing around words with no calculations or proofs to back them up," says Lee Smolin of the Perimeter Institute for Theoretical Physics in Waterloo, Canada, who has studied some of the papers.

But Roman Jackiw, a physicist at MIT who reviewed Igor's thesis, insists that it is of the requisite quality. Robert Coquereaux, from the International Centre for Mathematical Meetings in Marseille, has said that the brothers' work is certainly no better or worse than that of some established theoretical physicists.

The brothers, who are currently presenting a short television programme in France, insist that their work is genuine. They say that many critics haven't actually read their entire theses, which are available only in French, and that none of the criticisms made discredits their work. They also point to referees' reports on their theses. Verbaarschot, for example, declared that Igor's PhD "ranks as one of the best I have seen in recent years".

With no clear consensus emerging, the credibility of the peer-review system and journals in string theory and related areas is taking a battering. Peter Woit, a mathematician at Columbia University in New York, says that the incident illustrates the speculative nature of much theoretical physics. "The Bogdanoffs' work is significantly more incoherent than just about anything else being published," he says. "But the increasingly low standard of coherence in the whole field is what allowed them to think they were doing something sensible and to get it published."

\section{Health initiative gets warm welcome}

\section{Geoff Brumfiel, Washington}

Plans for a more integrated approach to the world's health problems are gathering momentum, according to their architect Richard Klausner, a former director of the US National Cancer Institute.

Klausner wants to increase the effectiveness of public-health campaigns in developing countries by merging areas such as economics and political science into public-health thinking. This field of 'global health sciences' would also foster connections between institutions in the developed and the developing world to bolster the public-health infrastructures of poorer nations.

During the six months since he became executive director of the global health programme at the Bill \& Melinda Gates Foundation in Seattle, Washington, Klausner has met with researchers across Europe and the United States to advocate the creation of the new field. "The people I've spoken to are very intrigued," he says.

"It's time to change how we do public health," agrees Josh Ruxin of the Center for Global Health and Economic Development at Columbia University in New York. Poverty, corruption and regional instability

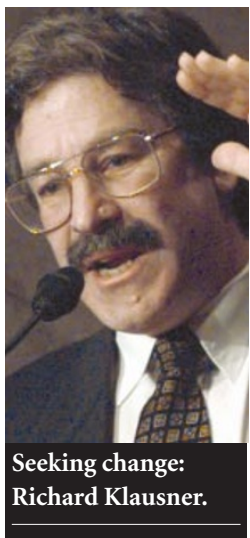

are often critical factors that determine how an epidemic unfolds. "But you don't learn how to deal with those issues in public-health schools," Ruxin says.

Partnerships between the developed and developing world are also essential to improving public health, adds Amir Attaran, a publicpolicy expert at

Harvard's John F. Kennedy School of Government. "There are astonishingly few scientific resources in developing countries," he says. Fostering research communities through collaboration would go a long way towards increasing the quality of public health, he suggests.

Klausner, who oversees half of the roughly US $\$ 1$ billion in grants given out by the Gates Foundation, is optimistic that institutions will take up his idea. "Stay tuned," he says. "I think a lot is going to happen in the next year or so." 